\title{
Entry Mode Decision Factors Contemplated by Chinese Consulting Firms
}

\author{
Dongjiang Huang $^{1} \&$ Krit Jarinto $^{2}$ \\ ${ }^{1}$ Dali City, Yunnan, China \\ ${ }^{2}$ Graduate School of Commerce of Burapha University, Chonburi, Thailand \\ Correspondence: Krit Jarinto, Graduate School of Commerce of Burapha University, 169 Longhard Bangsean \\ Rd., Chonburi 20131, Thailand. Tel: 66-38-394-900. E-mail: krit.dba1 @ gmail.com
}

Received: January 19, 2015

Accepted: February 4, 2015

Online Published: April 25, 2015

doi:10.5539/ibr.v8n5p252

URL: http://dx.doi.org/10.5539/ibr.v8n5p252

\begin{abstract}
The purposes of this study were to investigate the factors affecting the decision to choose entry mode to Thai market by Chinese consulting firms through the application of Uppsala model. The method of study focused on future research based on perception, recommendation, and prediction of participants since the researcher employed qualitative approached by In-depth interview of 16 experts to gain the necessary qualitative data. Though the analysis by experts, the most appropriate entry mode is Joint ventures, and the rest is Strategic Alliance and wholly owned subsidiaries. The economic situation, the foreign business laws and regulations and the needs of foreign clients are the top 3 important factors affecting the decision to choose entry mode to Thai market by Chinese consulting firms. Chinese management consulting industry is still in development and growth stage, expansion and merger is the trend, and the prospect of Chinese consulting firm business in Thailand is optimistic.
\end{abstract}

Keywords: foreign market entry mode, Uppsala model, Chinese consulting service business, Thai consulting service business, internationalization

\section{Introduction}

For more than 100 years, more Chinese business has been developed in Thailand. There are also many trading firms both in China and Thailand. Recently, the degree of trading between Thailand and China has become more and more intensive. Now Thailand has become the opening gate for China to enter into the ASEAN countries' market. Asia is considered to be the world's largest emerging market. As a founding member of ASEAN, Thailand is located in the Asian hinterland, also of strategic significance with strong market radiation (Artur Gradziuk, 2010).

When there is business develop or modern trade, another alternative to support the growth of investment is to provide consulting services. When the Chinese businesses are invested in Thailand, the company may need consultancy services to help them avoid the law dispute or other strategy decision in business development. It can be summarized that most consulting services provided in Asia have been managed by western consulting firms. The researcher has not found any active Chinese consulting companies in Thailand. It is believed that more Chinese business and industries will be invested in Thailand due to the trade agreement of ASEAN-China, which will create potential demand for Chinese consulting firms in Thailand. Chinese consulting firms want to open the global gate for entering into Thai market, which is an internationalization process. The theoretical research formulated by Johanson and Weidersheim-Paul (1975). Moreover, Johanson and Vahlne (1977) laid the foundation for comprehension the internationalization process of companies. The Uppsala model has illustrated the internationalization of a company as a process of experiential learning and incremental commitments which leads to an evolutionary development in a foreign market or an emerging market. (Daniel Tykesson \& Mikael Alserud, 2011).

\subsection{Objective of Research}

The objective of research is to investigate the factors affecting the decision to choose entry mode to Thai market by Chinese consulting firms through the application of Uppsala model. 


\subsection{Conceptual Framework}

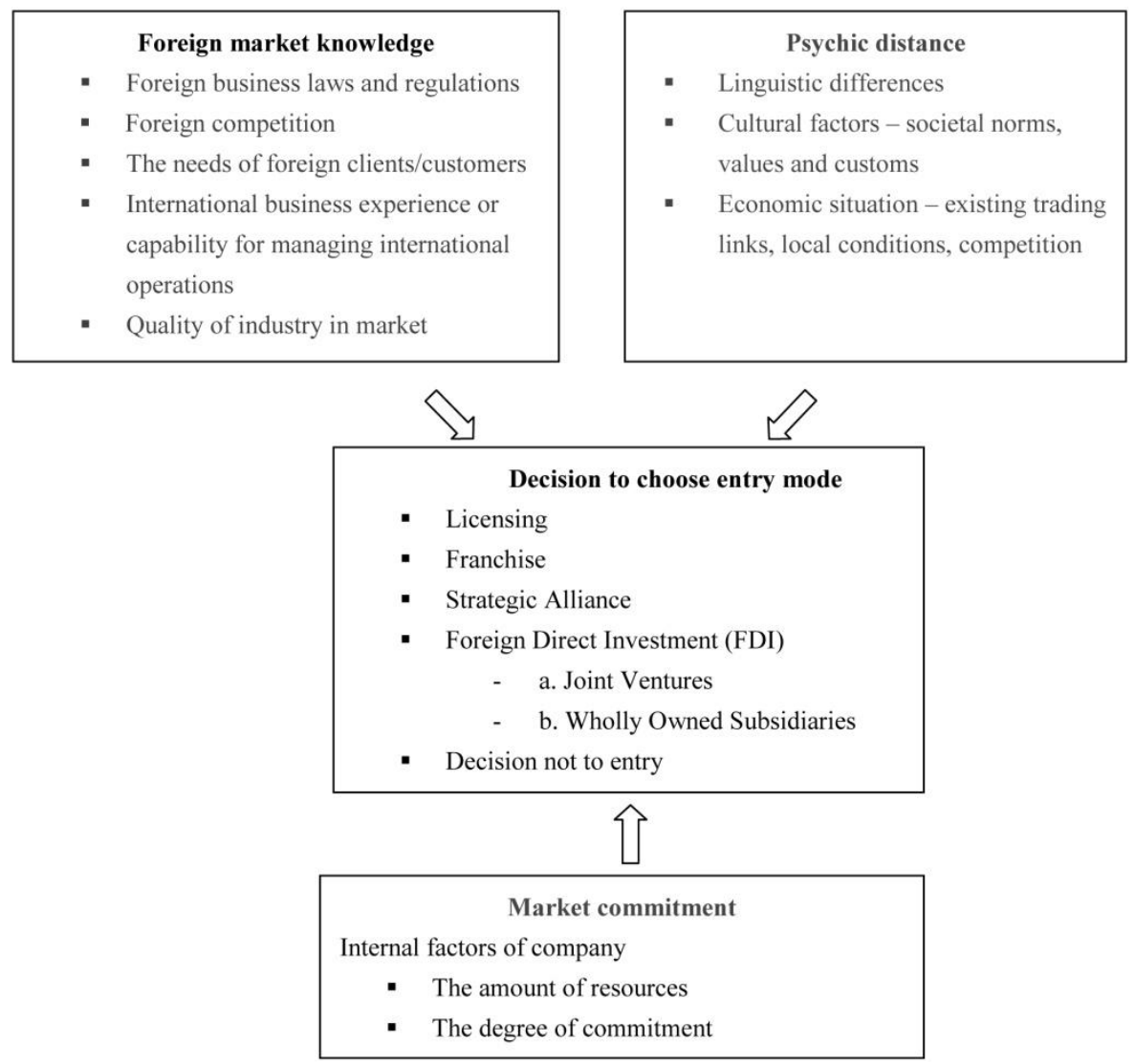

Figure 1. Conceptual framework

\section{Literature Review}

\subsection{Foreign Market Entry Mode}

The foreign market entry mode is an institutional arrangement for the entry of a firm's products or services into a new foreign market or an emerging market. It is the decision of how to enter into a foreign market or emerging market can have a significant impact on the result. Moreover, expansion into a foreign market is defined as the following four aspects: (Investopedia US, 2013)

1) Licensing

2) Franchise

3) Strategic Alliance

4) Foreign Direct Investment (FDI)
- $\quad$ a. Joint Ventures
- b. Wholly Owned Subsidiaries

\subsection{The Concept of Uppsala Model on Entry Mode}

The Uppsala model is related to behavioral theory of a firm. This theory explains how companies gradually increase their activities in foreign markets or an emerging market. The Uppsala model has described that the internationalization of a company as a process of experiential learning and incremental commitments. It leads to an evolutionary development in a foreign market or an emerging market. Johanson and Vahlne formulated this approach in 1977. Researcher mentioned that empirical observations on Swedish manufacturing firms from their studies at the international business department of Uppsala University (Johanson \& Vahlne, 1977). The Uppsala model is based on four key aspects: market commitment, market knowledge, current activities and commitment 
decisions. These four aspects are separated the state aspects and the change aspects. The two state aspects are market commitment and market knowledge. Market commitment is the resources committed to foreign markets. In addition, market knowledge is the knowledge about foreign markets and operations possessed by the company at a specific time. Moreover, the two change aspects are current activities and commitment decisions. Therefore, the last aspect is the decisions to commit resources to foreign operations.

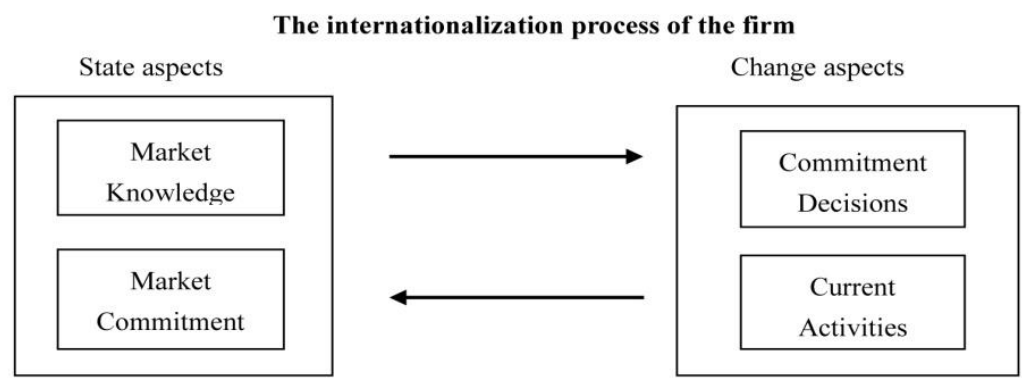

Figure 2. The internationalization process of the firm

Source: Johanson and Vahlne (1990), in Johanson and Associates, 1994, p. 84.

\subsection{Structure of Chinese Consulting Firms}

Structure of Chinese consulting industrial in the vertical can be divided into three levels: information consulting, management consulting and strategic consulting. Information consulting is the base layer of consulting business industry. Information on the level of market information and consulting company primarily engaged in the investigation, collection, collation and analysis of business, to provide accurate, complete auxiliary information for business decisions. Management consulting is the core layer of consulting business industry. The management consulting company in accordance with all levels of business management mainly is divided into specialized business areas, these areas generally include: investment and financing consulting, financial and accounting consulting, tax consulting, marketing consulting, human resources consulting, production and management consulting, business consulting, engineering and technical consulting, business process reengineering and management of information technology consulting Etc. Features of management consulting is general requirements for the project team composed by professional consultant and the corresponding business enterprise personnel while consulting operation to manage the transformation of enterprise management on some level or conduct a comprehensive transformation. Strategic consulting is the highest level of consulting business industry. In the management consulting firm which focus on strategic consulting service mainly for enterprises provide strategic design, competitive strategy, business analysis or planning and design services, and even there are some consulting firms mainly provide policy-making advice for government. Providing strategic consulting services and decision-making is difficult, and it is also difficult to see significant results. (China Consulting Industry Research, 2011).

\section{Research Methodology}

The method of study focused on future research based on perception, recommendation, and prediction of experts and participants in the Chinese services business and Thailand services business. Therefore, in order to answer the research questions and response to the objectives, the researcher employed qualitative approached by In-depth interview to gain the necessary qualitative data for the guidelines of the investigation.

This study applies content analysis to analyze data. It is the main strategy method in this study in order to investigate the factors affecting the decision to choose entry mode to Thai market by Chinese consulting firms through the application of Uppsala model, and to understand the potential capacity of internationalization of Chinese consulting firms in expanding overseas business based on various dimensions and procedural steps.

There is one main research instrument used in this study: ATLAS.ti. In this study, the ATLAS.ti as a qualitative data analysis (QDA) computer software is also used in qualitative data analyzing. The objective of ATLAS.ti is to help researchers illustrate and systematically analyze complex phenomena hidden in unstructured data (such as text, multimedia, geospatial). This software program provides tools that let the user locate, code, and annotate findings in primary data material. In addition, it can weigh and evaluate importance of the primary data resource. Moreover, ATLAS.ti can visualize the often complex relations between whole data material (Atlasti blog 
wordpress, 2014).

\subsection{Data Collection Process}

There are two significant steps of the investigation: (1) collecting data by In-depth interview experts, (2) making data analysis by response of In-depth interview with content analysis. There are the minimum of 16 experts that are knowledgeable in the scope of proposed factors. According to In-depth interview, they will be interviewed by the researcher. The interview may be performed up to 45-60 minutes until there is a concentric conclusion from the experts about what factors affecting the decision to choose entry mode to Thai market by Chinese consulting firms through the application of Uppsala model, and recommendation from the number of experts by using in-depth interview are separate into two groups, 8 of Thai experts and 8 of Chinese experts.

For comprehensive understanding, the tentative investigation of this process is shown as follows:

Step 1: Data was collected by In-depth interviews of 16 experts consisting of 8 Thai and 8 Chinese from review of the literature to organize selected factors for experts to make comments to investigate the factors affecting the decision to choose the entry mode to the Thai market by Chinese consulting firms through the application of the Uppsala model.

Step 2: Analysis by the content analysis method:

1). Identifying concepts. Decide on a certain number and set of concepts for coding, the existence or frequency of a concept, and then distinguish among the concepts. Taking the generalization of concepts into consideration, make the coding process a crucial level of consistency and coherence. Then, define relationship types.

2). Code the texts through the use of the computer programs ATLAS.ti. Coding with a computer is one of contemporary conceptual analysis' greatest assets. By inputting one's categories, content analysis programs can easily automate the coding process and examine huge amounts of data, and a wider range of texts, quickly and efficiently.

3). Analyze results by grouping the words or issues, or finding the relationships between the issues. Graphically displaying and numerically analyzing the resulting maps. The conceptual analyst is dealing only with quantitative data; the levels of interpretation and generalizability are very limited.

\section{Result of the Study}

The research findings presented the data analysis and theme analysis results from the voice of key informants about experts' experiences, ideas and facts about the phenomenon of Chinese consulting services business. Figure 3 revealed framework structure model to correspond the framework of this papers. 


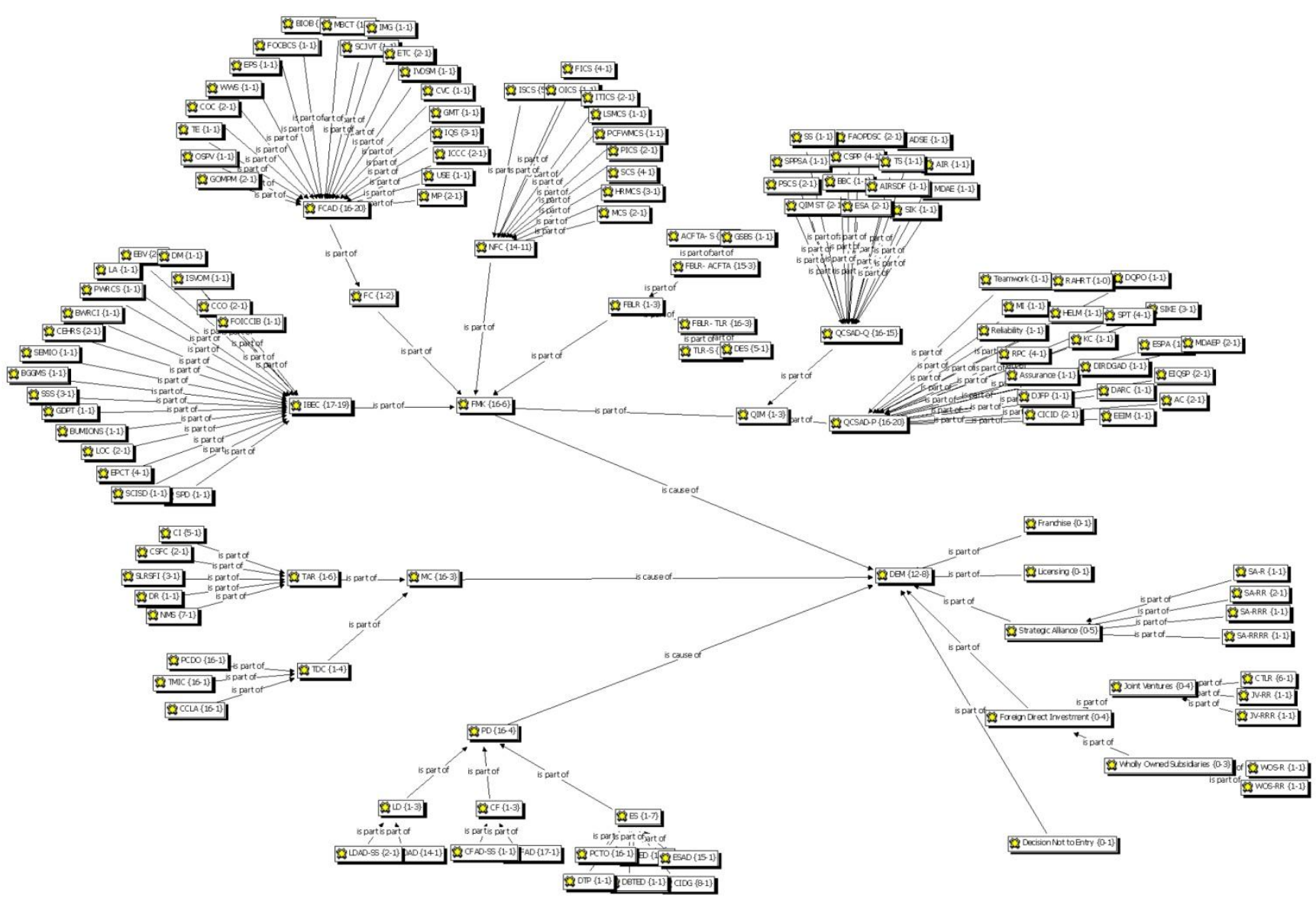

Figure 3. Framework structure model

After the analysis of interview resources, for the factors affecting the decision to choose entry mode, 16 participants had elaborated and provided a justification for their response. The result from finding the opinion about the most appropriate entry mode for Chinese consulting firms in Thailand, this issue had responded by the participants in this research as following:

- In foreign market entry mode issue, no one recommended choosing Licensing and Franchise these two entry mode. In addition, no participant mentioned the decision not to entry as well.

- Total 9 experts recommended Joint ventures as the most appropriate entry mode.

- About 5 experts choose Strategic Alliance as the most appropriate entry mode.

- 2 experts preferred wholly owned subsidiaries as the most appropriate entry mode.

The factors affecting the decision to choose entry mode to Thai market by Chinese consulting firms ranked as following base on the importance:

a. The factor of economic situation-existing trading links, local conditions, competition. Economic conditions have regressed. Investment environment is linked with political stability. Political unrest is bound to affect economic development, it's no doubt. Therefore, Thailand economic situation currently will have big impact on international investment certainly. These experts thought that recent political situation in Thailand is relatively unstable, so political instability will play a negative role on economic development of Thailand and then economic situation will affect the decision to choose entry mode. The reason of political instability will take a lot of risk in investment. Most foreign investors, especially private investors would remain hesitant. Most companies took a wait - and - see attitude toward the new investing environment.

b. The factor of foreign business laws and regulations. In participants' opinion, the impact from ASEAN-China Free Trade Agreement on Trade in Services for Chinese consulting business expanding to Thailand is a basic objective condition. Since the Chinese investor is expanding their business internally, the free trade agreement will promote the investment from Chinese. It will benefit to the Chinese consulting service. Policy supporting is 
in order to expand the further trade. Foreign business laws and regulations will ensure the foreign company be more official and formal.

c. The factor of the needs of foreign clients/customers. Most experts thought that the future demand for consulting services business will be higher and higher. Market openness in Thailand is very high. With the establishment of the ASEAN free trade, Thailand as pivotal role in ASEAN countries will become increasingly apparent. Rapid economic development, especially in expanding service sector of the market, will certainly promote the rapid development of advisory services. Therefore, the future demand will be high. This is a virtual certainty. Actually, in Southeast Asia, with the development of the service industry, the management consulting industry emerges as the times require. Due to changes in the modern enterprise management level and enhance the concept, the demand for management consulting are further increased. The development of consulting services business will become an inevitable trend.

d. The factor of quality of industry in market. In the experts' opinion, the quality of services is more important. Good quality is the foundation of all of this. As for the competitiveness of industry, it is also an objective reason. Quality needs to be defined and measured accurately. Like the problem-solve skill and communication skill of consultant, they can be considered the quality of services. For the how do Chinese consulting firms perform on these quality attribute, experts thought the company should equip with reasonable and professional consultants. And another one, the storage of information and knowledge should be very extensive to adapt the market economy constantly changing. Of cause, marketing deployment is accurate and efficient is another important factor, the market information is important, and the knowledge of consultant is important, too.

e. The factor of foreign competition. Most experts recommended that enhance the own management consulting firm competitiveness of Chinese company, calmly deal with the challenges of economic globalization. The rapid development of economic globalization, global enterprises to enter the competition stage without borders, management consulting multinational companies setting up shop in China this vibrant, contains enormous opportunities in the market. But on the other hand, China is a developing country, in general market development is not perfect, the main competitive strength is still relatively weak, the level of information to various reasons behind the management level is not high, and as a result of China's management consulting firm at a disadvantage in international competition.

f. The factor of cultural Factors-societal norms, values and customs. Learning and understanding Thai culture first when Chinese consulting firms want to enter into Thai market, learning how to do the business with Thai people. Of course, how to combine the Chinese business culture with Thai business culture together is a key point also. Experts thought that the business culture will be the important factor to affecting Chinese consulting firm to expanding into Thai market. Thai social culture is very different from Chinese culture. Do in Rome as Rome does may be their first obstacle. The culture diversity and understanding Thai business behavior is a key point as well. And Chinese companies have to follow the local culture for get more convenience in expanding business. For another side the Chinese must give more trust to Thai, mutual trust is very important. It is will influence the expanding of business.

g. The factor of international business experience or capability for managing international operations. Establishing brand advantage or brand effect maybe become important capability for managing international operations for Chinese consulting firms in Asia should be equipped. If Chinese consulting firms want to managing international operations should have own brand value. Unique brand value is a key point. Moreover, mutually beneficial cooperation with Thai local company is a key. A win-win strategy of development of consulting services business will take more benefit for Thai local clients and Chinese clients who had invested in Thailand. Mutually beneficial cooperation not only serves common prosperity and development of China and Thailand, but also contributes to trade of two countries. And, Chinese firms should relentlessly follow the open strategy of mutual benefit and win-win results and pursue a development of cooperation with Thai company.

h. The factor of the degree of commitment. Almost every expert thought that Chinese consulting firms cannot get high acceptability in Thai consulting market. Currently, the consulting services market in Thailand has no established Chinese consulting company. Thai consulting services industry most compose of Thai local company and global consulting business firms. Moreover, some experts thought that acceptability means satisfactoriness by virtue of conforming to approved standards. The acceptability and the company's brand effect is closely linked. Brand reputation value constitutes the main content of brand value. Then came the Chinese company will take some time to build a good reputation and credibility. The Chinese consulting industry should take some time to develop overseas business. Because Chinese consulting firms started later than west countries, so Chinese consulting need develop core competency first then can get high acceptability in Thai consulting market. 
i. The factor of linguistic differences. The most experts thought that linguistic differences will affect the decision to choose entry mode of Chinese consulting services in Thailand. Only few experts thought that linguistic differences have an impact on small-scale, but not the decisive factor. The reason they given is also tend to be consistent. Language is the basic tool transitional information and ideas, and it is dominant part of the cultural differences. Like we known, languages should possess certain common properties in optimizing the communication efficiency. Thus linguistic differences will make trouble in internationalization into target market. Linguistic differences can affect the accuracy of the communication from a certain extent.

j. The factor of the amount of resources. The most experts commented that stationed overseas markets at beginning should do enough market research to determine the scale of investment. Taking a conservative investment is a safety way. Any company will meet a lot trouble in the initial investment, so reduce investment risk is very important. They thought that the scale of investment is not too large. Chinese company should do the rational planning with relying on the strength of domestic companies. In general, to determine the scale of investment need according to situation of social demand and supply. Therefore, ensure the safe development of multinational companies. It is conducive to the achievement of global strategic objectives. Conservative investment is easy to spread the risk, stable economic benefits of enterprises. Of course, before the company takes any form of investment, we must make full market investigation.

\section{Conclusion}

Analyze the factors driving these entry modes:

(1) The factors drive the entry mode in Joint Ventures. Joint ventures often enable growth without having to borrow funds or look for outside investors. We may be able to use our joint venture partner's customer database to market your product, or offer our partner's services and products to our existing customers. Joint venture partners also benefit from being able to join forces in purchasing, research and development. The top 7 factors that drive this entry mode has ranked as shown as following base on the importance:

a. The factor of economic situation - existing trading links, local conditions, competition;

b. The factor of foreign business laws and regulations;

c. The factor of the needs of foreign clients/customers;

d. The factor of foreign competition;

e. The factor of cultural Factors - societal norms, values and customs;

f. The factor of international business experience or capability for managing international operations;

g. The factor of linguistic differences.

(2) The factors drive the entry mode in Strategic Alliance. A global strategic alliance is usually established when a company wishes to edge into a related business or new geographic market-particularly one where the government prohibits imports in order to protect domestic industry. The advantage is getting instant market access, or at least speed company entry into a new market and gain greater knowledge of international customs and culture as well. Enhance Chinese consulting firm's image in the world marketplace. The top 7 factors that drive this entry mode has ranked as shown as following base on the importance:

a. The factor of the degree of commitment;

b. The factor of economic situation - existing trading links, local conditions, competition;

c. The factor of foreign competition;

d. The factor of quality of industry in market;

e. The factor of international business experience or capability for managing international operations;

f. The factor of the needs of foreign clients/customers;

g. The factor of cultural Factors - societal norms, values and customs.

(3) The factors drive the entry mode in Wholly Owned Subsidiaries. A wholly-owned subsidiary can serve itself well by doing business in a separate location than the parent company because it is able to remain in its locale. This is especially important in international situations. Additionally, they can take advantage of one another's management and technical expertise, reduce administrative overlap and better integrate new product development and launch initiatives. The top 7 factors that drive this entry mode has ranked as shown as following base on the importance: 
a. The factor of economic situation - existing trading links, local conditions, competition;

b. The factor of the amount of resources;

c. The factor of foreign business laws and regulations;

d. The factor of the needs of foreign clients/customers;

e. The factor of the degree of commitment;

f. The factor of quality of industry in market;

g. The factor of international business experience or capability for managing international operations.

\section{Discussion}

The findings of this research were supported by extant literature and relative academic researches. In this research, the researcher also focused on understanding the potential capacity of Chinese consulting firms in expanding the business to Thailand. Like Alexander, Sanne, Leena, and Jonas (2009) express that the problems faced by management consultants in Asia are many. Managements in Asia is via networks and relationships. 'Act global, think local' applies even to management consultants. Name such as McKinsey \& Co. and Boston Consulting Group mean less in Asia than they do in the West. It will be their staff-the personalities-that count most when it comes to winning projects. As always, personal connections are everything. It is important that some measure of trust can be established. (Wall Street Journal, 13, June, 2001). However, expansion and mergers of management consulting business is a general trend, especially for many small domestic consulting firms, joint is the inevitable choice for development and growth, only expanding its own strength, to enhance the consulting market influence to the international competition leading management consulting companies survive.

\section{Recommendations for Future Study}

The directions of future study are suggested as:

1). Improvement of potential capacity of Chinese consulting firms in expanding the business to Thailand is a very important aspect for the future development of Chinese consulting service industry. The further study could be studying how to enhance Chinese consulting firms' overall competitiveness, create its own brand in the competitive international challenges, to gain a foothold in the international market.

2). Core strength of management consulting firm in the final analysis is the talent advantage. Management consulting services are offered exclusively through the minds of consultant experience and knowledge. Competition in the management consulting industry is the competition of talent. In the market is not a product but a consultant direct face to face, provided the product is not the product but the production line flowing consultant minds comprehensive knowledge and experience of the results. Therefore, the further study could be studying how to enhance the talent advantage in Chinese consulting service company.

3). Domestic management consulting firm project cost is generally lower than the multinational consulting company, but sometimes difficult to ensure quality of service. So, how to improve the quality of service is an important strategic objective. Therefore, the further study could be studying how to improve the quality of Chinese consulting service industry.

\section{References}

Adams, C., \& Sherer, P. M. (1998). The wall street journal Asia. Retrieved from http://www.readabstracts.com/author/the-wall-street-journal-western-edition-1998/other/

Alexander, S., Sanne, O., Leena, W., \& Jonas, R. (2010). Expert or speaking-partner? Shifting roles and identities in consulting work. Leadership \& Organization Development Journal, 31(2), 159-175.

Atlasti. (2014). About ATLAS.ti. Retrieved from https://atlastiblog.wordpress.com/

Backman, M., \& Butler, C. (2004). Big in Asia: 25 strategies for business success. Basingstoke: Palgrave.

China Management Consulting Industry Report. (2010). Retrieved from http://charlieweijer.blogspot.com/2013/04/china-as-new-market-for-management.html

Gradziuk, A. (2010). Implications of ASEAN-China Free Trade Agreement (ACFTA). USA: The Polish Institute of International Affairs.

Johanson, J., \& Vahlne, J. E. (1977). The internationalization process of the firm-a model of knowledge development and increasing foreign market commitments. Journal of International Business Studies, 8, 22-32. http://dx.doi.org/10.1057/palgrave.jibs.8490676 
Johanson, J., \& Vahlne, J. E. (1990). The mechanism of internationalization. International Marketing Review, 7(4), 11-24. http://dx.doi.org/10.1108/02651339010137414

Johanson, J., \& Vahlne, J. E. (1992a). Management of foreign market entry. Scandinavian International Business Review, 1(3), 9-27. http://dx.doi.org/10.1016/0962-9262(92)90008-T

Johanson, J., \& Vahlne, J. E. (1992b). Subsidiary influence and autonomy in international firms. Scandinavian International Business Review, 1(3), 84. http://dx.doi.org/10.1016/0962-9262(92)90010-4

Johanson, J., \& Weidershiem, P. F. (1975). The internationalization of the firm: Four Swedish cases. Journal of Management Studies, 12(3), 305-322. http://dx.doi.org/10.1111/j.1467-6486.1975.tb00514.x

Mckinsey and Chinese Client Spar over Quality of Service. (2008, June). Wall Street Journal, 13.

Tykesson, D., \& Alserud, M. (2011). The Uppsala model's applicability on internationalization processes of European SMEs today: A case study of three small and medium sized enterprises. German: LUNDS University.

Welch, L. S., \& Luostarinen, R. (1988). Internationalization: Evolution of a concept. Journal of General Management, 14(2), 34-55.

\section{Appendix}

\section{Interview Guidelines}

1) How many years have you been working for a consulting service firm? In your work, the most clients are from which field (manufacturing industry, education industry, financial industry, etc.? Please list.

2) What do you think about future demand for consulting services business in Thailand? Please explain.In your opinion, what kind of service that firms in Thailand would like to need from consulting firms? Will these services demand change for Chinese consulting firms?

3) What do you think about the impact from ASEAN-China Free Trade Agreement on Trade in Services for Chinese consulting business expanding to Thailand? Will it be supported or obstacle to Chinese consulting business to Thailand? Please explain.

4) For the high competition among the current consulting services industry, what are the requirements for Chinese consulting service industry have to satisfy in order to succeed in Thailand? Please provide a justification for your response.

5) What capability for managing international operations for Chinese consulting firms in Asia should be equipped? Please elaborate and provide a justification for your response.

6) What is your opinion for the quality of consulting service business should comprise of? Please elaborate and provide a justification for your response. In your opinion, how do Chinese consulting firms perform on these quality attribute?

7) For the potential size of investment, what recommendation for Chinese consulting service company to enter into Thai market?

8) With your experience, how much acceptability that Chinese consulting firms have in Thai consulting market? Please explain.

9) As tools of communication, languages should possess certain common properties in optimizing the communication efficiency. Do you think the linguistic differences will affect the decision to choose entry mode of Chinese consulting services in Thailand? And how about Chinese consulting service business culture?

10) What is your opinion about Thailand economic situation? Do you think it will have impact on international investment? Please elaborate.

11) With your experience, how do you think for the prospects of Chinese consulting service business in Thailand? It's optimistic or not? Why?

12) According to your opinion, what is the appropriate entry mode for Chinese consulting firms in Thailand? a. Licensing, b. Franchise, c. Strategic Alliance, d. Foreign Direct Investment (FDI): Joint ventures and wholly owned subsidiaries, or decision not to entry. Please explain. 


\section{Copyrights}

Copyright for this article is retained by the author(s), with first publication rights granted to the journal.

This is an open-access article distributed under the terms and conditions of the Creative Commons Attribution license (http://creativecommons.org/licenses/by/3.0/). 